\title{
Fish consumption and risk of rheumatoid arthritis: a dose-response meta-analysis
}

\author{
Daniela Di Giuseppe*, Alessio Crippa, Nicola Orsini and Alicja Wolk
}

\begin{abstract}
Introduction: The association between fish consumption and rheumatoid arthritis (RA) is unclear. The aim of this paper was to summarize the available evidence on the association between fish consumption and risk of RA using a dose-response meta-analysis.

Methods: Relevant studies were identified by a search of MEDLINE and EMBASE through December 2013, with no restrictions. A random-effects dose-response meta-analysis was conducted to combine study specific relative risks. Potential non-linear relation was investigated using restricted cubic splines. A stratified analysis was conducted by study design.

Results: Seven studies (four case-controls and three prospective cohorts) involving a total of 174701 participants and 3346 cases were included in the meta-analysis. For each one serving per week increment in fish consumption, the relative risk (RR) of RA was 0.96 (95\% confidence interval (Cl) 0.91 to 1.01). Results did not change when stratifying by study design. No heterogeneity or publication bias was observed. When fish consumption was modeled using restricted cubic splines, the risk of RA was 20 to 24\% lower for 1 up to 3 servings per week of fish ( $R R=0.76,95 \% \mathrm{Cl}: 0.57$ to 1.02 ) as compared to never consumption.
\end{abstract}

Conclusions: Results from this dose-response meta-analysis showed a non-statistically significant inverse association between fish consumption and RA.

\section{Introduction}

Rheumatoid arthritis (RA) is an inflammatory autoimmune disease that affects the joints, leading to cartilage and bone destruction. The worldwide prevalence of this chronic disease ranges between $0.5 \%$ and $1.0 \%$ [1]. Smoking [2] and alcohol consumption [3,4] have been linked to the development of RA, but little is known about other modifiable risk factors. Among dietary factors, fish consumption is of particular interest due to its role in primary prevention of several chronic diseases, including cardiovascular disease $[5,6]$. Moreover, fish is rich in long-chain n-3 polyunsaturated fatty acids, which have been shown to be beneficial in primary [7] and secondary prevention [8] of RA.

The association of fish consumption with risk of developing RA is still unclear, because results from both casecontrol and cohort studies are mixed. One prospective cohort [7] and two case-control studies $[9,10]$ have

\footnotetext{
* Correspondence: daniela.digiuseppe@ki.se

Division of Nutritional Epidemiology, Institute of Environmental Medicine, Karolinska Institutet, Nobels vag 13, Stockholm 171 77, Sweden
}

observed an inverse association between fish consumption and RA risk, but results were not statistically significant. On the other side, two prospective $[11,12]$ and two case-control studies $[13,14]$ did not show an association with total fish consumption.

The aim of the present study was to quantitatively summarize the published evidence from epidemiological studies on the association between fish consumption and RA using a dose-response meta-analysis.

\section{Methods}

We conducted a literature search through December 2013 using PubMed and EMBASE databases. The term, rheumatoid arthritis, was used in combination with fish, or seafood. Reference lists from acquired articles were also examined. Studies were included in the meta-analysis if they met the following inclusion criteria: the exposure was fish or seafood consumption; the outcome was incident RA; relative risk (RR) or odds ratio (OR) estimates were reported with their $95 \% \mathrm{CI}$. 
From each study we collected information on the first author's last name, publication year, country, study period, number of cases and controls or cohort size, gender and age of study participants, covariables adjusted for, and RRs or ORs with $95 \% \mathrm{CI}$ for each exposure category. If multiple RRs and ORs were presented, we extracted the estimates from the maximally adjusted model in order to reduce the risk of possible unmeasured confounding. Data extraction was performed independently by two of the authors (DDG and AC).

The quality of studies was assessed using the NewcastleOttawa quality assessment scale (NOQAS) for cohort and case-control studies, with which each study was judged based on the selection of the study groups, the comparability of the groups, and the ascertainment of exposure and outcome [15]. The score ranged between 0 (as poor) and 9 (as excellent). The present work follows the recommendations of the preferred reporting items for systematic reviews and meta-analyses (PRISMA) Statement [16]. This study did not need ethical approval or consent from patients.

\section{Statistical analyses}

A two-stage dose-response random-effects meta-analysis was conducted to combine risk estimates [17-19]. The dose-response relationship curves were estimated by taking into account the covariance among risk estimates for different exposure categories [18]. The midpoint between the upper and lower boundary of each category was assigned to the corresponding risk estimate. For open-ended lowest categories, the lower bound was considered as zero, while the open-ended highest categories were assumed to be of the same amplitude as the preceding categories. For the study of Di Giuseppe et al. [7], the mean fish consumption within each exposure level was obtained from the primary data. Results from a study that reported only the linear association for grams per day of fish consumption were rescaled to servings per week [12].

A potential non-linear relation between fish consumption and RA risk was investigated using restricted cubic splines with three knots at fixed percentiles $(10 \%, 50 \%$, and $90 \%$ ) of the exposure distribution. Departure from linearity was assessed by testing the null hypothesis that the coefficient of the second spline was equal to zero [20]. The study by Pedersen et al. was excluded from the flexible dose-response analysis because it reported information only on the linear trend [12].

In all meta-regression models, statistical heterogeneity between studies was evaluated with the Cochran Q-test and the $I^{2}$ statistic [21] that assesses the proportion of total variation due to between-study variation. Publication bias was investigated by the Egger regression asymmetry test [22]. Sensitivity analyses were conducted by stratifying for study design and by excluding one study at the time to evaluate if results were particularly influenced by single studies. Statistical analyses were performed with $\mathrm{R}$ software, version 3.0.2, using the packages metafor and dosresmeta [23].

\section{Results}

Of the 384 studies identified through PubMed and EMBASE, only seven examined the association between fish consumption and risk of RA and were included in this dose-response meta-analysis (Figure 1). Characteristics of the included studies are showed in Table 1. Three studies were prospective cohorts $[7,11,12]$ and included 170,986 participants, of which 820 developed RA during the follow-up time $(2,212,395$ person-years), while four studies were of case-control design $[9,10,13,14]$, of which two had hospital-based $[9,13]$ and two had populationbased controls [10,14], including a total of 2,526 cases and 3,715 controls. Three of the studies analyzed RA risk only among women $[7,11,14]$, while the remaining analyzed both men and women $[9,10,12,13]$. Three studies adjusted only for age and gender [9,12,13], while other took into account other possible confounding factors, such as smoking $[7,10,11]$ and total energy intake $[7,11,14]$. Only one study adjusted for other dietary factors, such as red meat and dairy product consumption [7]. Using the NOQAS quality assessment, the seven studies were assessed to have moderate quality.

Three studies showed a borderline statistically significant inverse association between total fish consumption and risk of RA $[7,9,10]$, while the others reported no association (Figure 2). Only two studies analyzed type-specific fish consumption [12,14]. A statistically significant inverse association was found between fatty fish and risk of RA in

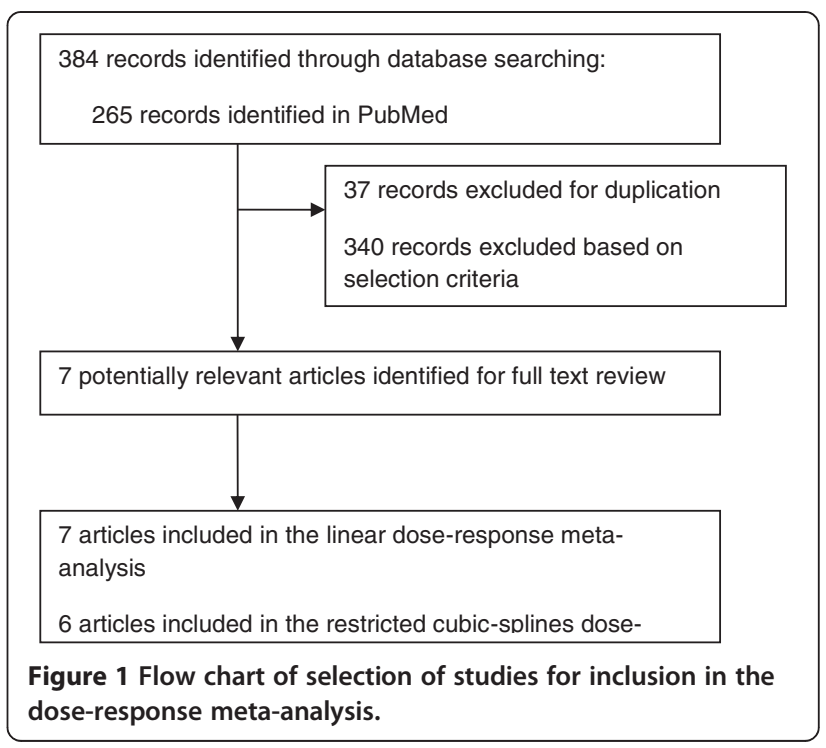


Table 1 Characteristics of studies on rheumatoid arthritis and fish consumption

\begin{tabular}{|c|c|c|c|c|c|c|}
\hline Author, year & $\begin{array}{l}\text { Study population, } \\
\text { country, follow-up } \\
\text { period/study period }\end{array}$ & $\begin{array}{l}\text { Cases/cohort } \\
\text { size or controls }\end{array}$ & $\begin{array}{l}\text { Gender, age } \\
\text { (years) }\end{array}$ & $\begin{array}{l}\text { Relative risk/odds } \\
\text { ratio }(95 \% \mathrm{Cl})\end{array}$ & Controlled variables & NOQAS $^{2}$ \\
\hline \multicolumn{7}{|l|}{ Cohort } \\
\hline Pedersen et al., 2005 [12] & $\begin{array}{l}\text { Diet, Cancer and } \\
\text { Health cohort, } \\
\text { Denmark, } 1993 \text { to } \\
2001\end{array}$ & $69 / 56691$ & $\begin{array}{l}\text { Men and women, } \\
50 \text { to } 64\end{array}$ & $\begin{array}{l}\text { Per } 30 \text { g/day: } 0.91 \\
(0.68,1.23)\end{array}$ & Age and gender & 6 \\
\hline \multirow[t]{5}{*}{ Benito-Garcia, 2007 [11] } & \multirow[t]{5}{*}{$\begin{array}{l}\text { Nurses' Health Study, } \\
\text { USA, } 1980 \text { to } 2002\end{array}$} & \multirow[t]{5}{*}{$546 / 82063$} & \multirow[t]{5}{*}{ Women, 30 to 55} & $\begin{array}{l}\left.\text { Q1 (median } 0.07 \mathrm{~s} / \mathrm{d}^{1}\right) \text { : } \\
1.00(\text { ref) }\end{array}$ & \multirow{5}{*}{$\begin{array}{l}\text { Age, total energy } \\
\text { intake, body mass } \\
\text { index, smoking, total } \\
\text { lifetime breastfeeding }\end{array}$} & \multirow[t]{5}{*}{7} \\
\hline & & & & $\begin{array}{l}\text { Q2 }(0.13 \mathrm{~s} / \mathrm{d}): 0.94 \\
(0.73,1.23)\end{array}$ & & \\
\hline & & & & $\begin{array}{l}\mathrm{Q} 3(0.17 \mathrm{~s} / \mathrm{d}): 1.09 \\
(0.81,1.47)\end{array}$ & & \\
\hline & & & & $\begin{array}{l}\text { Q4 }(0.25 \mathrm{~s} / \mathrm{d}): 1.06 \\
(0.80,1.40)\end{array}$ & & \\
\hline & & & & $\begin{array}{l}\text { Q5 }(0.44 \mathrm{~s} / \mathrm{d}): 0.96 \\
(0.72,1.26)\end{array}$ & & \\
\hline \multirow[t]{8}{*}{$\begin{array}{l}\text { Di Giuseppe et al., } 2013 \\
\text { [7] }\end{array}$} & \multirow{8}{*}{$\begin{array}{l}\text { Swedish } \\
\text { Mammography } \\
\text { Cohort, } 2003 \text { to } 2010\end{array}$} & \multirow[t]{8}{*}{ 205/32 232} & \multirow[t]{8}{*}{ Women, 54 to 89} & $\begin{array}{l}\text { <1 s/w nel 1987, } \\
\text { <1 s/w nel 1997: }\end{array}$ & \multirow{8}{*}{$\begin{array}{l}\text { Age, cigarette } \\
\text { smoking, alcohol } \\
\text { intake, use of aspirin, } \\
\text { red meat } \\
\text { consumption, dairy } \\
\text { food consumption, } \\
\text { energy intake }\end{array}$} & \multirow[t]{8}{*}{8} \\
\hline & & & & 1.00 (ref) & & \\
\hline & & & & $\begin{array}{l}\geq 1 \text { s/w nel 1987, } \\
<1 \text { s/w nel 1997: }\end{array}$ & & \\
\hline & & & & $0.78(0.50,1.22)$ & & \\
\hline & & & & $\begin{array}{l}<1 \mathrm{~s} / \mathrm{w} \text { nel 1987, } \\
\geq 1 \mathrm{~s} / \mathrm{w} \text { nel 1997: }\end{array}$ & & \\
\hline & & & & $1.01(0.66,1.56)$ & & \\
\hline & & & & $\begin{array}{l}\geq 1 \mathrm{~s} / \mathrm{w} \text { nel 1987, } \\
\geq 1 \mathrm{~s} / \mathrm{w} \text { nel 1997: }\end{array}$ & & \\
\hline & & & & $0.71(0.48,1.04)$ & & \\
\hline \multicolumn{7}{|l|}{ Case-control } \\
\hline \multirow[t]{3}{*}{ Linos et al., 1991 [9] } & \multirow{3}{*}{$\begin{array}{l}\text { Hospital-based } \\
\text { controls, Greece }\end{array}$} & \multirow[t]{3}{*}{$168 / 137$} & \multirow{3}{*}{$\begin{array}{l}\text { Men and women, } \\
24 \text { to } 89\end{array}$} & $1-2 \mathrm{~s} / \mathrm{m}^{1}: 1.00$ (ref) & \multirow[t]{3}{*}{ Age and gender } & \multirow[t]{3}{*}{5} \\
\hline & & & & $\begin{array}{l}4-10 \mathrm{~s} / \mathrm{m}: 0.64 \text { (0.38, } \\
1.08)\end{array}$ & & \\
\hline & & & & $\begin{array}{l}12+\mathrm{s} / \mathrm{m}: 0.37(0.13 \\
1.05)\end{array}$ & & \\
\hline \multirow[t]{4}{*}{ Shapiro et al., 1996 [14] } & \multirow{4}{*}{$\begin{array}{l}\text { Population-based } \\
\text { controls, USA, } 1986 \text { to } \\
1991\end{array}$} & \multirow[t]{4}{*}{$324 / 1245$} & \multirow[t]{4}{*}{ Women, 18 to 64} & $<1 \mathrm{~s} / \mathrm{w}: 1.00$ (ref) & \multirow{4}{*}{$\begin{array}{l}\text { Reference age, } \\
\text { reference year, } \\
\text { education, race, total } \\
\text { caloric intake }\end{array}$} & \multirow[t]{4}{*}{8} \\
\hline & & & & $1-<2$ s/w: 0.87 & & \\
\hline & & & & $(0.62,1.21)$ & & \\
\hline & & & & $\begin{array}{l}\geq 2 \mathrm{~s} / \mathrm{w}: 0.92(0.67 \\
1.25)\end{array}$ & & \\
\hline \multirow[t]{4}{*}{ Linos et al., 1999 [13] } & \multirow[t]{4}{*}{$\begin{array}{l}\text { Hospital-based } \\
\text { controls, Greece }\end{array}$} & \multirow[t]{4}{*}{$145 / 188$} & \multirow[t]{4}{*}{$\begin{array}{l}\text { Men and women, } \\
18 \text { to } 84\end{array}$} & $\begin{array}{l}\text { Q1 (median } 3 \mathrm{~s} / \mathrm{w} \text { ): } \\
1.00 \text { (ref) }\end{array}$ & \multirow[t]{4}{*}{ Age and gender } & \multirow[t]{4}{*}{5} \\
\hline & & & & $\begin{array}{l}\text { Q2 (4 s/w): } 1.21 \\
(0.64,2.29)\end{array}$ & & \\
\hline & & & & $\begin{array}{l}\text { Q3 (6 s/w): } 0.90 \\
(0.47,-1.71)\end{array}$ & & \\
\hline & & & & $\begin{array}{l}\text { Q4 (10 s/w): } 0.95 \\
(0.46,1.96)\end{array}$ & & \\
\hline
\end{tabular}


Table 1 Characteristics of studies on rheumatoid arthritis and fish consumption (Continued)

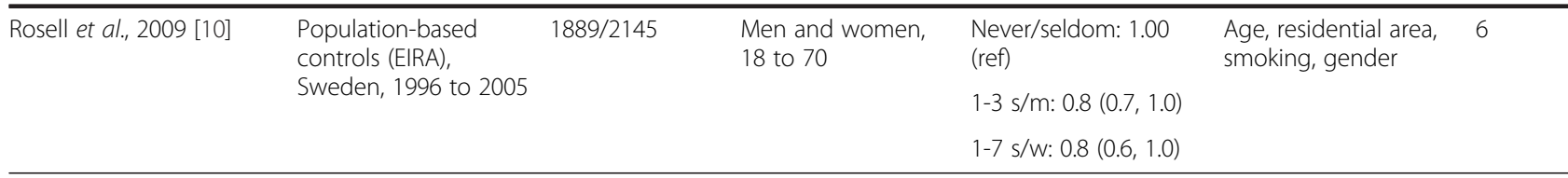

Information on fish consumption was collected using food frequency questionnaires in all studies. ${ }^{1} \mathrm{~s} / \mathrm{d}=$ servings per day, $\mathrm{s} / \mathrm{w}=\mathrm{servings}$ per week, $\mathrm{s} / \mathrm{m}=\mathrm{servings}$ per month. NOQAS, Newcastle-Ottawa Quality Assessment Scale (score from 0 as poor to 9 as excellent).

the study of Pedersen et al. [12], which, however, observed an increased risk for medium-fat fish consumption [12]. Broiled or baked fish was inversely associated with RA in the study of Shapiro et al. [14].

We first assumed a linear-response model for the association between fish consumption and risk of RA. The risk of RA decreased by $4 \%$ for every increase of one fish serving per week, although this change was not statistically significant ( $R R=0.96,95 \%$ CI 0.91, 1.01) (Figure 3). There was no evidence of heterogeneity across the studies $\left(I^{2}=\right.$ $0.0 \%, P$-value $=0.41)$ or of publication bias $(P$-value $=0.27)$. Results stratified by study design were similar: the pooled
RR was 0.96 (95\% CI 0.91, 1.01) and 0.97 (95\% CI 0.90, 1.05) for case-control and for cohort studies respectively. We also stratified by number of covariates considered: the pooled RR of the three studies that adjusted only for age and gender was 0.88 (95\% CI 0.74, 1.05), while it was 0.97 (95\% CI 0.93, 1.02) for the four studies that considered also covariates other than age and gender. A sensitivity analysis excluding one study at the time showed that the linear trend ranged between 0.95 (95\% CI 0.91, 1.00) and 0.97 (95\% CI 0.93, 1.01).

We next allowed departure from linearity by fitting a spline model. We found no statistically significant

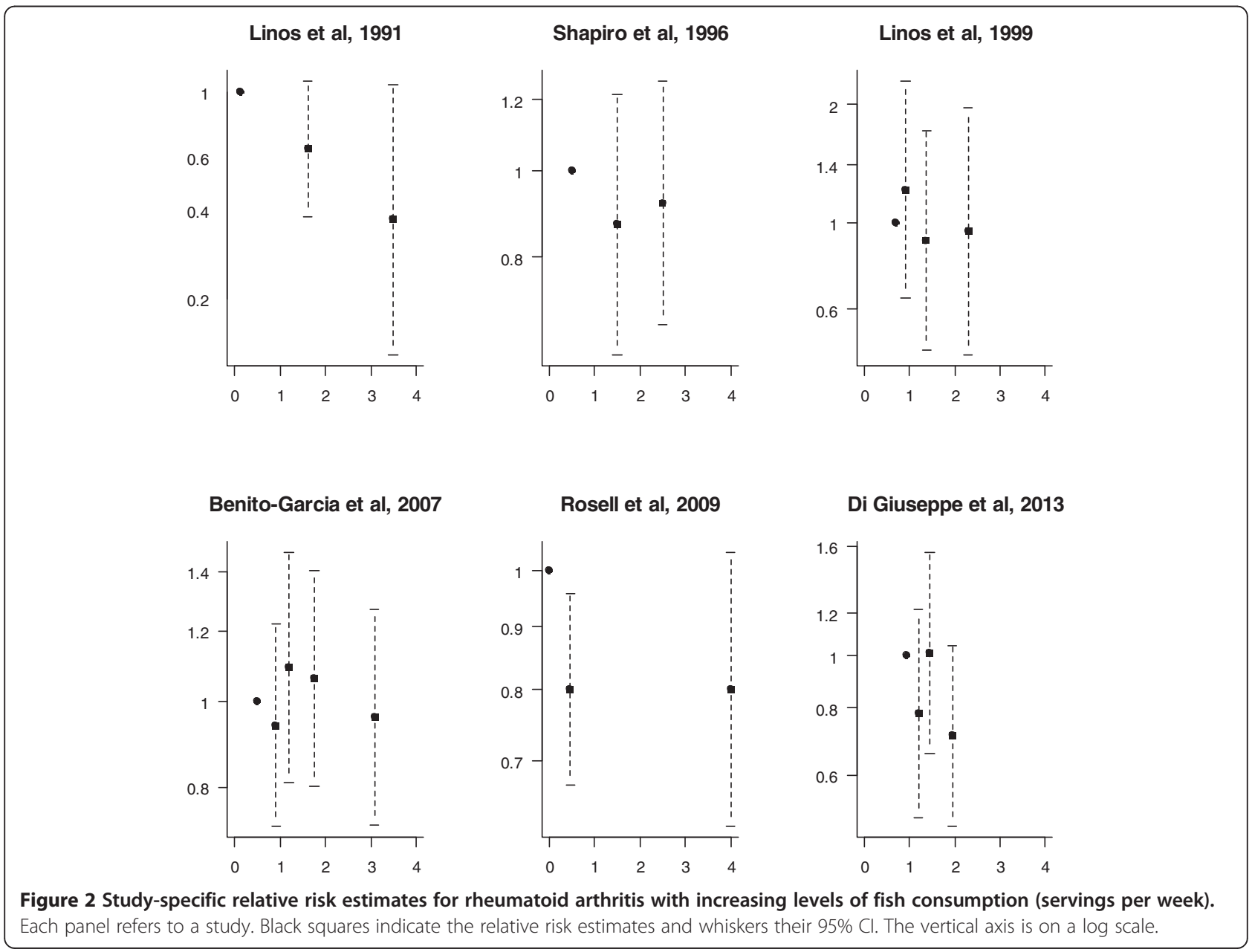




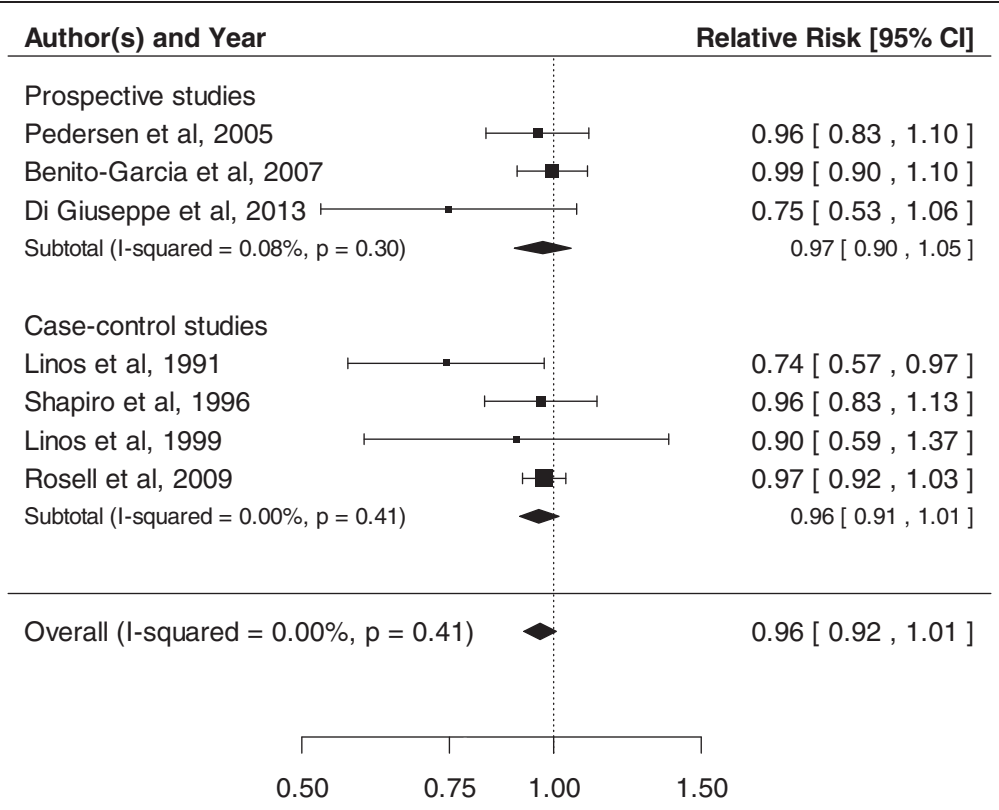

Figure 3 Relative risk of rheumatoid arthritis for every one serving per week increase in fish consumption.

departure from a linear association between fish consumption and RA risk $\left(P_{\text {non-linearity }}=0.15\right)$ (Figure 4). However, the plot of the relative risk based on the flexible approach showed a decrease in risk for up to two servings per week, followed by a slight increase in risk for higher consumption. Compared with no fish consumption, one, two and three servings per week were associated with $20 \%$ ( $R R=0.80,95 \%$ CI $0.62,1.04$ ), $24 \%$ $(\mathrm{RR}=0.76,95 \% \mathrm{CI} 0.57,1.02)$ and $20 \%(\mathrm{RR}=0.80,95 \%$ CI $0.65,0.99$ ) lower RA risk, respectively.

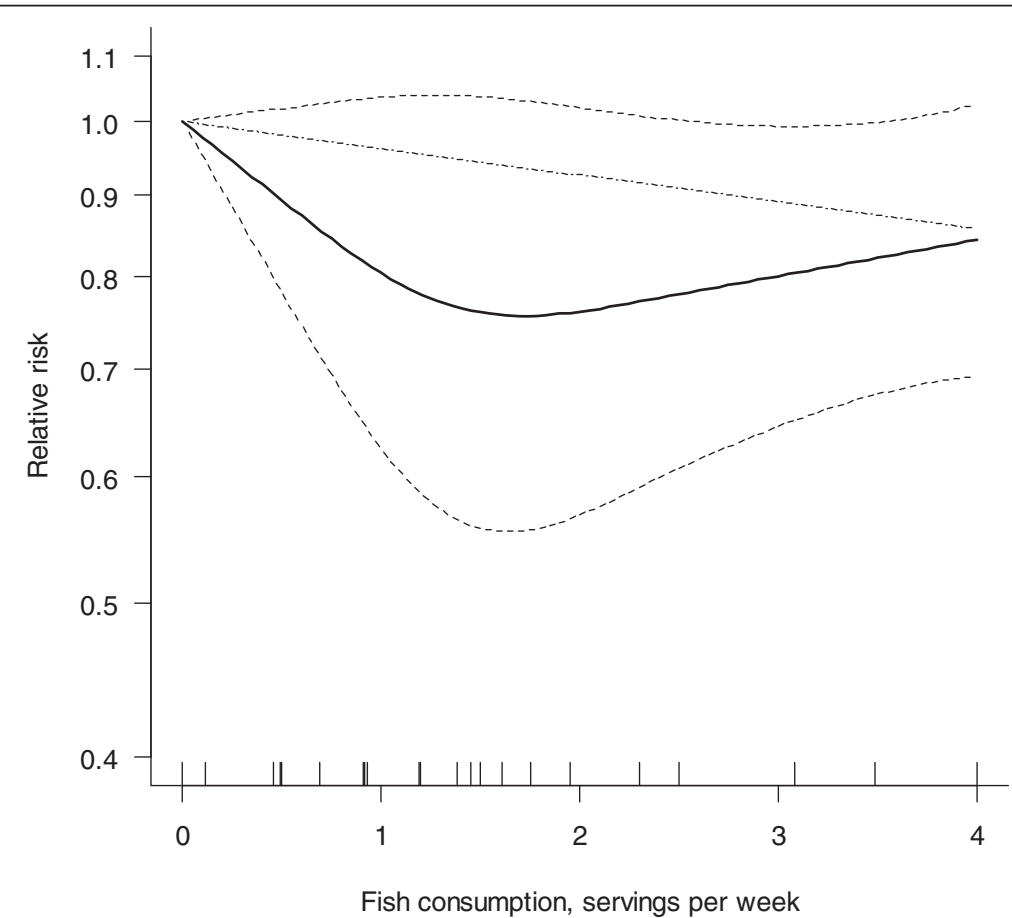

Figure 4 Pooled dose-response association between fish consumption and rheumatoid arthritis risk (solid line). Fish consumption was modeled with restricted cubic splines in a multivariate random-effects dose-response model. Dashed lines represent the $95 \% \mathrm{Cl}$ for the spline model. The dotted line represents the linear trend. Tick marks below the curve represent the positions of the study-specific relative risks. The value of 0 servings per week served as referent. The relative risks are plotted on the log scale. 


\section{Discussion}

The present study is the first dose-response meta-analysis on the association between fish consumption and risk of developing RA. Results from this meta-analysis showed a weak inverse association between total fish consumption and risk of RA. The flexible non-linear approach for modeling fish consumption showed a decrease in RA risk for one to three servings per week of fish consumption, followed by a slight increase in risk for higher consumption.

The inverse association between fish consumption and risk of developing RA observed in some of the studies has been mainly attributed to its content of long-chain n-3 polyunsaturated fatty acids (PUFAs) $[7,10,14]$. Indeed, when long-chain n-3 PUFAs are included in the analysis model the inverse association between fish and RA disappears [7]. A possible reason behind this inverse association is the anti-inflammatory properties of these fatty acids. In fact, the n-3 PUFA eicosapentaenoic acid (EPA) and docosahexaenoic acid (DHA) are metabolized to competitive inhibitors of n-6 PUFAs (prostaglandins and leukotrienes) and suppress the production of the inflammatory cytokines [24]. The lack of a statistically significant inverse association observed in this meta-analysis could be explained by the balance of the protective effect of long-chain n-3 PUFAs with the presence of contaminants such as polychlorinated biphenyls (PCBs), which have been found to be positively associated with RA [25]. Moreover, the presence of PCBs could explain why in the study of Shapiro et al., the inverse association was statistically significant only for broiled or baked fish and not for total fish consumption, as the presence of PCBs is lower in cooked fish [26].

The main strength of this meta-analysis is its doseresponse design, that provides better quantification of the associations between specified amounts of fish and risk of RA. A dose-response meta-analysis should be the preferred option when performing a systematic review, rather than running a meta-analysis based only on the comparison of the extreme categories of consumption (high versus low), which could vary considerably among studies.

Among the limitations, a meta-analysis is deeply influenced by the quality of the single studies included. Results could be over- or underestimated due to residual confounding. Of the seven studies included in this metaanalysis, three $[9,12,13]$ adjusted only for age and gender, and therefore their results could be affected by residual confounding by factors such as smoking and total energy intake. This meta-analysis summarizes results from both prospective cohort and case-control studies. However, these two types of study design have many differences, including the different statistical estimate (hazard ratio versus odds ratio) and different biases. In fact, despite all studies using a food frequency questionnaire (FFQ) to assess fish consumption, participants in prospective cohort studies received the FFQ when they were disease-free, while in case-control studies, the cases received the FFQ after diagnosis, leading to a possible recall bias. Also, the RA diagnosis could be misclassified. Of the seven studies included in the meta-analysis, two prospective cohort studies identified cases by linkage with national health registers $[7,12]$, while one prospective cohort used selfreported RA cases that were subsequently validated [11], a method that could have led to under-detection of cases who did not self-report RA. Due to the limited number of studies, it was not possible to stratify according to country to evaluate if the differences in fish consumption between countries could have influenced the results of the metaanalysis. Moreover, there were also differences in the representativeness of the general population in the single studies: studies from Scandinavia $[7,10,12]$ represented their respective general populations well, while the level of representativeness of the other studies is less clear.

\section{Conclusion}

In conclusion, the summary estimates from this doseresponse meta-analysis show a non-statistically significant inverse association between fish consumption and RA.

\begin{abstract}
Abbreviations
FFQ: food frequency questionnaire; NOQAS: Newcastle-Ottawa quality assessment scale; OR: odds ratio; PCB: polychlorinated biphenyl;

PUFA: polyunsaturated fatty acid; RA: rheumatoid arthritis; RR: relative risk.
\end{abstract}

\section{Competing interest}

The authors declare that they have no competing interests.

\section{Authors' contributions}

DDG, AC, NO, and AW participated in the study design and in writing the manuscript. DDG, AC and NO participated in the data collection. DDG and $A C$ analyzed the data and wrote the manuscript under the supervision of AW. DDG, NO, AW interpreted the data and critically reviewed the paper. All authors read and approved the final manuscript

\section{Acknowledgements}

This work was supported by research grants from the Swedish Research Council/Committee for Medicine, and from the Swedish Research Council/ Committee for Research Infrastructure for maintenance of the Swedish Mammography Cohort. Ms Di Giuseppe was supported by the Karolinska Institutet Award for PhD students.

Received: 6 May 2014 Accepted: 29 August 2014

Published online: 30 September 2014

\section{References}

1. Gibofsky A: Overview of epidemiology, pathophysiology, and diagnosis of rheumatoid arthritis. Am J Manag Care 2012, 18:S295-S302.

2. Di Giuseppe D, Discacciati A, Orsini N, Wolk A: Cigarette smoking and risk of rheumatoid arthritis: a dose-response meta-analysis. Arthritis Res Ther 2014, 16:R61.

3. Jin Z, Xiang C, Cai Q, Wei X, He J: Alcohol consumption as a preventive factor for developing rheumatoid arthritis: a dose-response metaanalysis of prospective studies. Ann Rheum Dis 2013.

4. Scott IC, Tan R, Stahl D, Steer S, Lewis CM, Cope AP: The protective effect of alcohol on developing rheumatoid arthritis: a systematic review and meta-analysis. Rheumatology (Oxford) 2013, 52:856-867.

5. Li YH, Zhou CH, Pei HJ, Zhou XL, Li LH, Wu YJ, Hui RT: Fish consumption and incidence of heart failure: a meta-analysis of prospective cohort studies. Chin Med J (Engl) 2013, 126:942-948. 
6. Rudkowska I, Ouellette C, Dewailly E, Hegele RA, Boiteau V, Dube-Linteau A, Abdous B, Proust F, Giguere Y, Julien P, Chateau-Degat ML, Vohl MC: Omega-3 fatty acids, polymorphisms and lipid related cardiovascular disease risk factors in the Inuit population. Nutr Metab (Lond) 2013, 10:26.

7. Di Giuseppe D, Wallin A, Bottai M, Askling J, Wolk A: Long-term intake of dietary long-chain $\mathrm{n}-3$ polyunsaturated fatty acids and risk of rheumatoid arthritis: A prospective cohort study of women. Ann Rheum Dis 2013.

8. Lee YH, Bae SC, Song GG: Omega-3 polyunsaturated fatty acids and the treatment of rheumatoid arthritis: a meta-analysis. Arch Med Res 2012, 43:356-362.

9. Linos A, Kaklamanis E, Kontomerkos A, Koumantaki Y, Gazi S, Vaiopoulos G, Tsokos GC, Kaklamanis P: The effect of olive oil and fish consumption on rheumatoid arthritis-a case control study. Scand J Rheumatol 1991, 20:419-426.

10. Rosell M, Wesley AM, Rydin K, Klareskog L, Alfredsson L: Dietary fish and fish oil and the risk of rheumatoid arthritis. Epidemiology 2009, 20:896-901.

11. Benito-Garcia E, Feskanich D, Hu FB, Mandl LA, Karlson EW: Protein, iron, and meat consumption and risk for rheumatoid arthritis: a prospective cohort study. Arthritis Res Ther 2007, 9:R16.

12. Pedersen M, Stripp C, Klarlund M, Olsen SF, Tjonneland AM, Frisch M: Diet and risk of rheumatoid arthritis in a prospective cohort. J Rheumatol 2005, 32:1249-1252.

13. Linos A, Kaklamani VG, Kaklamani E, Koumantaki Y, Giziaki E, Papazoglou S, Mantzoros CS: Dietary factors in relation to rheumatoid arthritis: a role for olive oil and cooked vegetables? Am J Clin Nutr 1999, 70:1077-1082.

14. Shapiro JA, Koepsell TD, Voigt LF, Dugowson CE, Kestin M, Nelson JL: Diet and rheumatoid arthritis in women: A possible protective effect of fish consumption. Epidemiology 1996, 7:256-263.

15. Wells $G$, Shea B, O'Connell D, Welch V, Losos M, Tugwell P: The NewcastleOttawa Scale (NOS) for assessing the quality of nonrandomised studies in metaanalyses. [http://www.ohri.ca/programs/clinical_epidemiology/ oxford.asp]

16. Liberati A, Altman DG, Tetzlaff J, Mulrow C, Gotzsche PC, loannidis JP, Clarke M, Devereaux PJ, Kleijnen J, Moher D: The PRISMA statement for reporting systematic reviews and meta-analyses of studies that evaluate healthcare interventions: explanation and elaboration. BMJ 2009, 339:b2700.

17. Greenland S, Longnecker MP: Methods for trend estimation from summarized dose-response data, with applications to meta-analysis. Am J Epidemiol 1992, 135:1301-1309.

18. Orsini N, Bellocco R, Greenland S: Generalized least squares for trend estimation of summarized dose-response data. Stata J 2006, 6:40-57.

19. Liu Q, Cook NR, Bergstrom A, Hsieh CC: A two-stage hierarchical regression model for meta-analysis of epidemiologic nonlinear dose-response data. Comput Stat Data An 2009, 53:4157-4167.

20. Orsini N, Greenland S: A procedure to tabulate and plot results after flexible modeling of a quantitative covariate. Stata J 2011, 11:1-29.

21. Higgins JP, Thompson SG: Quantifying heterogeneity in a meta-analysis. Stat Med 2002, 21:1539-1558.

22. Sterne JA, Egger M, Smith GD: Systematic reviews in health care: Investigating and dealing with publication and other biases in meta-analysis. BMJ 2001, 323:101-105.

23. Crippa A, Orsini N: Dosresmeta: Performing multivariate dose-response meta-analysis. [http://CRAN.R-project.org/package=dosresmeta]

24. Cleland LG, Hill CL, James MJ: Diet and arthritis. Baillieres Clin Rheumatol 1995, 9:771-785

25. Lee DH, Steffes M, Jacobs DR: Positive associations of serum concentration of polychlorinated biphenyls or organochlorine pesticides with self-reported arthritis, especially rheumatoid type, in women. Environ Health Perspect 2007, 115:883-888.

26. Hori T, Nakagawa R, Tobiishi K, lida T, Tsutsumi T, Sasaki K, Toyoda M: Effects of cooking on concentrations of polychlorinated dibenzop-dioxins and related compounds in fish and meat. J Agric Food Chem 2005, 53:8820-8828.

\section{doi:10.1186/s13075-014-0446-8}

Cite this article as: Di Giuseppe et al: Fish consumption and risk of rheumatoid arthritis: a dose-response meta-analysis. Arthritis Research \& Therapy 2014 16:446.

\section{Submit your next manuscript to BioMed Central and take full advantage of:}

- Convenient online submission

- Thorough peer review

- No space constraints or color figure charges

- Immediate publication on acceptance

- Inclusion in PubMed, CAS, Scopus and Google Scholar

- Research which is freely available for redistribution

Submit your manuscript at www.biomedcentral.com/submit
C Biomed Central 